\title{
Faith for Earth Programme
}

\section{IYAD ABUMOGHLI}

PRINCIPAL COORDINATOR OF UNITED NATIONS ENVIRONMENT PROGRAMME'S FAITH FOR EARTH INITIATIVE

In John 4:IO, Jesus said, 'If you knew the gift of God and who it is that asks you for a drink, you would have asked him and he would have given you living water.' In The Holy Quran, The Prophets Chapter 2I verse 30 states: 'We made from Water Every Thing Living.' Indeed, water is central to all living things, but also to virtually all development strategies, especially as part of the 2030 Development Agenda and the Sustainable Development Goals.

Water priorities and programmes feature in the strategic plans of many development institutions, public and private, secular and faith-inspired. However, there is a large disconnect between the calls to assure clean water and decent sanitation for all world citizens as a matter of rights and justice, and the realities of complex and often poorly harmonised policies and programmes on the ground.

Due to human-induced climate change, polar ice caps are melting into oceans and mixing with salty water, causing a further loss of freshwater sources and sea-level rise.

- The discharge of the 80 per cent of all our wastewater, untreated, into rivers and lakes pollutes our waters.

- Some 800 children die each day due to preventable water and sanitationrelated diseases.

- Around 2 billion people do not have access to a safely managed water systems.

- Floods and other water-related disasters account for 70 per cent of all deaths related to natural disasters.

These facts are just some of the facts that are the reality of the water situation today. Half of humanity now lives in cities and, within two decades, nearly 60 per cent of the world's population will be urban dwellers. Urban growth is 
most rapid in the developing world, where cities gain an average of 5 million residents every month. The exploding urban population creates unprecedented challenges, of which provision of water and sanitation is the most pressing and has painful consequences when lacking.

Two main challenges related to water are affecting the sustainability of human urban settlements: the lack of access to safe water and sanitation, and increasing water-related disasters such as floods and droughts. This leaves cities with the daunting challenge of managing the risks of increased flooding, a dearth of drinking water, and polluted water. Not only the poor suffer the consequences of these challenges, but they pay more to get their basic needs. For example, a slum dweller in Nairobi, Kenya, pays between five and seven times more for a litre of water than an average North American citizen.

In 2018, flooding affected more people than any other disaster type. In the past year, there were 315 natural disaster events recorded with 12,000 deaths, over 68 million people affected, and US\$131.7 billion in economic losses around the world. Flooding not only affects human lives, but also the health and well-being of wildlife and livestock. This reduces the level of biodiversity, habitat potential, and food present in ecosystems, creating long-term impacts for surviving wildlife.

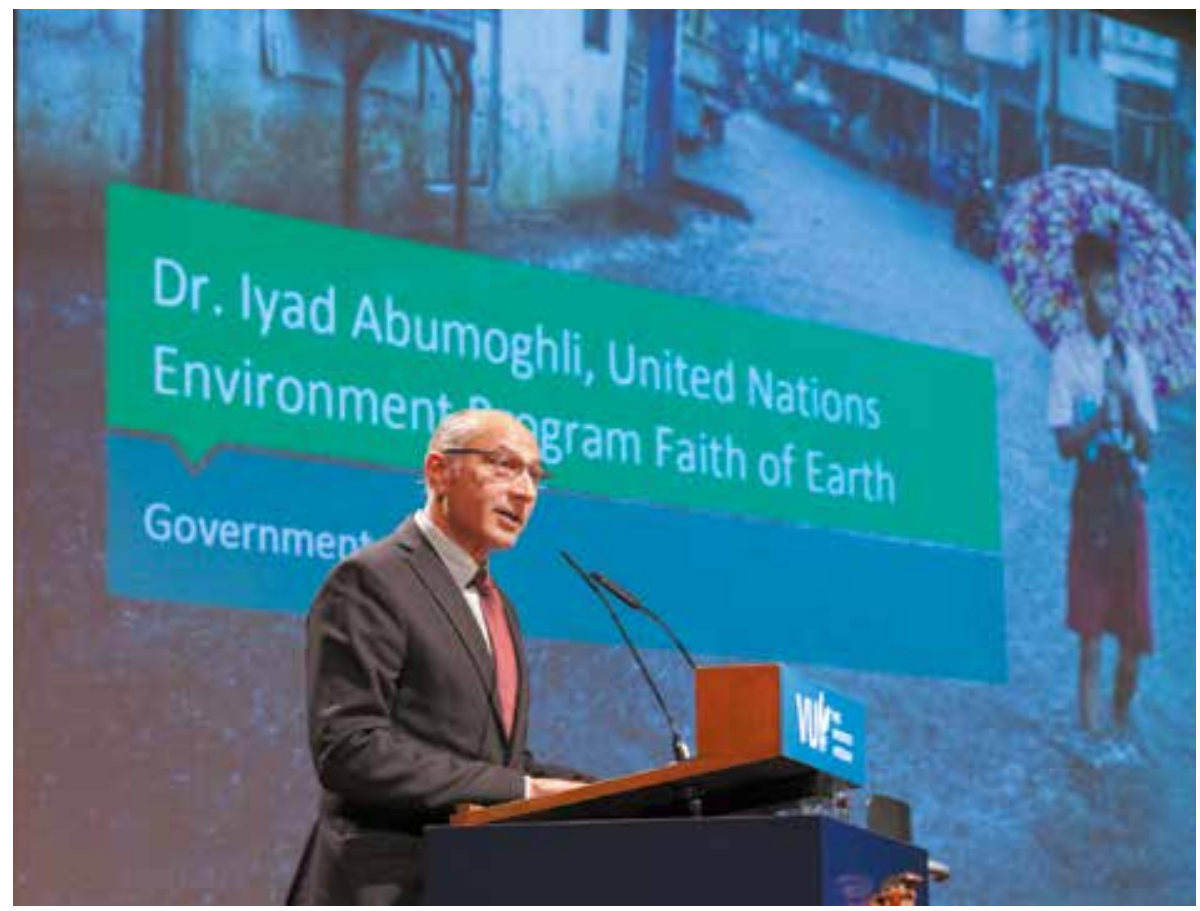


In August 2019, the UN Security Council met to discuss the growing new threats to world peace and security. Around 80 countries jointly agreed that the greatest impending threats to humanity were likely to be triggered not by terrorism, nuclear war or conflicts around the world, but by climate change. Climate change migration is one of the most challenging issues facing humanity, not in the future, but now. The threat of rising sea levels, caused by climate change, could result in a new category of 'environmental migrants' escaping from their sinking homes to neighbouring countries. The increased frequency, severity, and magnitude of extreme weather events all over the world will continue to generate humanitarian crises. Fluctuations between too much water and too little will have significant political, social, environmental, and economic consequences. If not managed effectively in a fair and inclusive manner, water can be a conflict driver.

Despite the complexity of the challenges, water is also a resource for collaboration. While the past 50 years have seen around 40 acute violent water conflicts, some 150 water treaties were signed around the world. An integrated approach to addressing the nexus of climate change, water management, and cities, is essential to fully account for the social, economic, political, and security impacts at both the local and the global levels.

To implement the 2030 Agenda and the Sustainable Development Goals, the United Nations Environment Programme (UNEP) and other UN agencies are providing advisory service packages, at global, regional, and national levels, on water management strategy. UNEP has developed strategies and taken on projects with global multi-stakeholder partnerships comprising governments, intergovernmental agencies, academia, the private sector, and civil society. UNEP is advancing the Integrated Water Resources Management, a process promoting the coordinated development and management of water, land, and related resources to maximise economic and social welfare in an equitable manner without compromising the sustainability of vital ecosystems. For example, Indonesia's Java island, seat of the capital Jakarta, accounts for 57.5 per cent of the country's population but has only 4.2 per cent of the country's water resources. Moreover, all six of its rivers are heavily polluted. UNEP has been working with the authorities and stakeholders to improve the poor Integrated Water Resources Management (IWRM) in Indonesia, where the severest obstacle to water management in the country is financing, in the interim, while capacity building and institutional frameworks are long-term concerns. The UNEP is implementing Flood and Drought Management Tools in the Wadi El $\mathrm{Ku}$ Catchment Management Project in Sudan to address water-related conflicts 
and disasters. It has become clear that only through dialogue can water be well managed, secure peace, and strengthen identities.

Practically, religions and culture can address climate change, biodiversity loss, pollution, desertification, and unsustainable land and water use by promoting a positive behaviour change. 84 per cent of the global population associates with a religion. UNEP's Faith for Earth Initiative is a strategy to mobilise faith-based organisations (FBOs), communities, individuals, and other entities through advocacy with religions on environmental issues. Our aim is to strengthen partnerships with FBO leadership for policy impact, to green FBO assets, and to transform the financing of the Sustainable Development Goals while presenting science-faith-based evidence. We are establishing the first ever global coalition of faith leaders on global environmental issues. This coalition will not only include eminent faith leaders, but also the young men and women who will become the leaders of tomorrow. A council for young faith leaders will be able to mobilise masses of youth to advocate for and engage in finding solutions to the global environmental crisis.

UNEP has been engaging with young people over the past decade. In September 2019, youth leaders from more than 140 countries and territories were invited to a Climate Action Summit to share their solutions on the global stage, and to deliver the clear message to world leaders that we must act now to address climate change. With direction and support from His Holiness Cardinal Turkson, in July 2019, UNEP hosted the 2nd International Conference of the 4th anniversary of Laudato $\mathrm{Si}$, with the participation of more than 300 young faith leaders who committed to engage at the global, regional, and local levels. The UN's ActNow Campaign is a call for individual effort. Tackling the climate emergency requires effort from all sectors of society. Also in September 2019, seven young environmental champion prize winners were endorsed by UNEP for their astonishing contributions to sustainable development progress. Twenty-oneyear-old Brazilian Anna-Luisa Beserra, who designed a cistern solution for clean water, won the prestigious Young Champions of the Earth Prize in Latin America and the Caribbean. Molly Burhan was the first faith leader to win the prize for mapping land owned by the Catholic Church to measure its carbon footprint.

Mobilising partnerships is essential for tackling water issues and climate change. Engaging and partnering with faith-based organisations is a vital way of capitalising on the cultural diversity and the ethical values of religions. The Faith for Earth Initiative is actively committed to ensuring that the sound stewardship of natural resources is a fundamental human value and responsibility. 


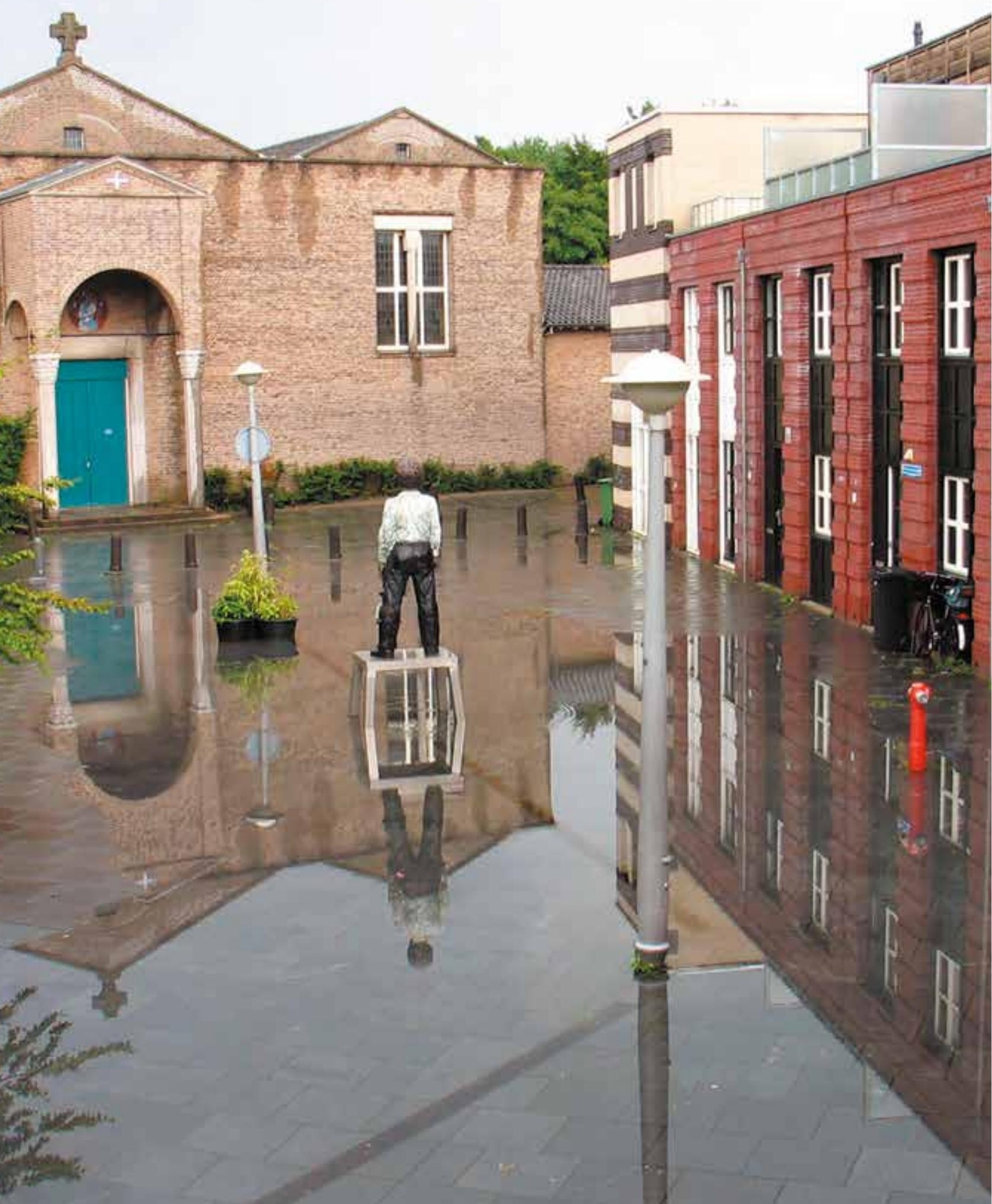

